The Polish Journal of the Arts and Culture. New Series 5

(1/2017): 51-65 [ARTYKUะ]

DOI: $10.4467 / 24506249$ PJ.17.003.6810

\title{
Konstrukt tsuchigumo jako mitologizacja zagrożenia
}

\author{
Renata IwICKA
}

\begin{abstract}
Streszczenie
Wczesną wyobraźnię mieszkańców Archipelagu Japońskiego pobudzała istota zwana tsuchigumo. Pająk ziemny był demonem straszliwym i krwiożerczym. Hordy takich pająków napadały na graniczne wioski i osiedla, porywając i mordując mieszkańców. Bliższe spojrzenie na obszar aktywności demonicznych pająków prowadzi do ciekawego wniosku - teren ich działalności pokrywał się z ziemiami, na których ludność miejscowa stawiała skuteczny opór grupie Yamato, z której wyrosła przyszła Japonia. Lęk przed obcością i wrogiem, jak wszędzie na świecie, zmienił obce dla Yamato plemiona w demoniczne pająki. Tsuchigumo pozostaje do dzisiaj interesującą próbą powiązania tendencji demonizacji Obcego z wyobraźnią mitologiczną i artystyczną i jako takie zjawisko to stanowi przedmiot wciąż nowych interpretacji.
\end{abstract}

Słowa kluczowe: Japonia, pająk, Obcość, tsuchigumo

Renata IwICKA orientalistka i kulturoznawczyni, adiunkt w Katedrze Porównawczych Studiów Cywilizacji Uniwersytetu Jagiellońskiego. Jej zainteresowania badawcze obejmują historię i kulturę Azji Wschodniej, popkulturę oraz antropologię kultury. Wybrane publikacje: Japonia w (pękniętym) lustrze Zachodu wedtug Ryūnosuke Akutagawy [w:] Spojrzenia. Japonia wedtug Zachodu, Zachód wedtug Japonii, A. Wosińska (red.), Toruń 2013, s. 63-79; Użycie roślin w telewizyjnych serialach fantastycznych, „Maska” 27/2015, s. 159-170.

E-MAIL: grad_ecmaise@yahoo.com 
Pająki nie należą do szczególnie lubianych zwierząt niezależnie od czasu i miejsca. Nadawano im przeróżne znaczenia symboliczne, ale u większości ludzi do dziś budzą strach, niechęć, niekiedy odrazę ${ }^{1}$. Elizabeth Caspari, podając przykłady pajęczych istot obecnych w wielu mitologiach, stwierdza, że są one „ogólnie fascynujące, powszechnie uważane za symbole cierpliwości i tkactwa, ale jednocześnie budzące lęk jako trucicielskie, zdradzieckie i odrażające" ${ }^{2}$. w Japonii również, we wczesnym okresie rozwoju państwowości, powstały legendy opowiadające o gigantycznych pajęczych istotach, które nękały dalekie rubieże formującego się państwa. Były to tsuchigumo ${ }^{3}$, czyli dosłownie „pająki ziemne”4.

Pająki ziemne pojawiły się w bardzo specyficznym momencie w dziejach Japonii, mianowicie w czasie, kiedy państwo dopiero się kształtowało (czyli do VIII wieku), co zawęża zakres badawczy, teoretycznie ułatwiając wyprowadzenie genezy. Jednak całościowy obraz pochodzenia konstruktu tsuchigumo jest dużo bardziej skomplikowany i zawiera kilka nakładających się źródeł zawierających wyobrażenia pajęczych istot. Jest to połączenie zarówno mitologii Yamato, skupionej wokół jednego rodu, jak i głębokiej niechęci do obcych grup etnicznych, żywionej przez przedstawicieli dominującej grupy, co w efekcie dało splątany i momentami niejasny obraz tsuchigumo ${ }^{5}$. W wiekach formowania się państwa japońskiego archipelag zamieszkiwały

${ }^{1}$ Jest to chyba jedyne zwierzę, które doczekało się tylu negatywnie nacechowanych, dowcipnych memów, w których występuje jako powód opuszczenia Ziemi, ataku nuklearnego, ofensywy armii, użycia miotacza płomieni oraz wyprowadzki z Australii.

2 E. Caspari, K. Robbins, Animal Life in Nature, Myth and Dreams. Wszystkie tłumaczenia, o ile nie podano inaczej, są przekładami autorskimi.

3 土蜘蛛.

4 Istniały również yamagumo (山蜘蛛), czyli pająki górskie, większość legend i mitów o pajęczych istotach dotyczy jednak tsuchigumo. Czasami różnica pomiędzy tymi gatunkami była nieznaczna.

5 Więcej na ten temat można znaleźć w pozycjach japońskojęzycznych: K. Shiratori, Tsuchigumo densetsu ni tsuite 土蜘蛛傳説に就いて [O legendach na temat tsuchigumo], s. 373-383; Y. Matsumoto, Tsuchigumoron 土蜘蛛論 [Teorie tsuchigumo], s. 434-455; K. Baba, Tsuchigumo no kenkyū: fō 「土蜘蛛」の研究-上- [Badania nad tsuchigumo, t. 1]; idem, Tsuchigumo no kenkyū: Chū 「土蜘蛛」の研究-中- [Badania nad tsuchigumo, t. 2]; idem, Tsuchigumo no kenkyū: Ge「土蜘蛛」の研究-下- [Badania nad tsuchigumo, t. 3]; K. Okiura, Nihon rettō no senjūmin: Tsuchigumo - sono denshō no chi o aruku 日本列島の先住民・土蜘蛛 その伝承の地を歩く [Pierwotni mieszkańcy Archipelagu fapońskiego: tsuchigumo - wędrówki po ich legendarnych ziemiach], s. 30-52; Y. Kubota, Tsuchigumo kenkyū ni okeru kadai to tenbō 土蜘蛛研究における課題と展望 [Tematy i zagadnienia $w$ badaniach nad tsuchigumo], s. $167-175$. 
różne grupy etniczne, przy czym przedstawiciele jednej z nich, określanej jako Yamato, skupili władzę centralną we własnych rękach ${ }^{6}$. Aby ukonstytuować władanie posiadanym terytorium i prawa do kolejnych podbijanych terenów, opracowano mitologię dominującego rodu, spisaną na początku VIII wieku jako kronika Kojiki. Druga księga, ukończona kilka lat później, Nihongi, dodawała kilka nowych elementów do poprzednich przekazów. Mitologia ta dawała pełnię władzy tylko jednej grupie etnicznej z uwagi na fakt, że na jej czele stał potomek samej bogini Amaterasu7 ${ }^{7}$. Pozostałe zostały podbite jako grupy obce, nie-Yamato, wykluczone. Akceptacja zwierzchności Yamato niwelowała odrębność etniczną, włączała to, co obce, w krąg familiarności ${ }^{8}$. „Obcość” jest zatem kategorią, bez której nie można w pełni zrozumieć zjawiska „upająkowienia” dzikich rubieży. Z tego też względu w niniejszej pracy oparłam się na koncepcji Obcości zaproponowanej przez Bernharda Waldenfelsa, który pisał, że „[za] obce uchodzi to, co wykluczone jest z kolektywnej sfery własnego i oddzielone od kolektywnej egzystencji [...]. Obcość w tym sensie oznacza brak przynależności do pewnego »my«" . w dawnej Japonii do kategorii Obcego należały wszystkie grupy nienależące do Yamato. W epokach późniejszych (począwszy od schyłkowego Heian), kiedy państwo zmieniło się już w jednolitą grupę określaną jako Japończycy i zabrakło „naturalnie" obcych etnicznie plemion, kategoria Obcości zaczęła obejmować pewne wyszczególnione, objęte rytualnym tabu ${ }^{10}$ grupy wewnętrzne - burakumin, czyli osoby wyrzucone poza rytm zwyczajnego życia japońskiego, a także obcokrajowców (określanych często jako ijin - obcych) oraz zainichi ${ }^{11}$.

6 Za: J. E. Kiddler, Himiko and Japan's Elusive Chiefdom of Yamatai: Archaeology, History, and Mythology.

7 Która według najnowszych danych jest konstruktem całkowicie sztucznym, wzorowanym na solarnych bóstwach państw Półwyspu Koreańskiego, nałożonym na rozmaite kulty lokalne. Por. T. Matsumae, Origin and Growth of the Worship of Amaterasu.

8 Interesującą analogią jest współczesna sytuacja zainichi (patrz przypis 10), którzy bardzo często nie mówią językiem przodków a tylko japońskim, nigdy nie wyjechali z Japonii, ale w dalszym ciągu nie posiadają statusu Japończyków. Przekroczeniem granicy i włączeniem w krąg familiarności jest moment zmiany nazwiska na japońskie. Część zainichi decyduje się na taki krok z uwagi na korzyści płynące z posiadania japońskiego obywatelstwa (edukacja, ubezpieczenia zdrowotne, etc.).

9 B. Waldenfels, Topografia obcego. Studia z fenomenologii obcego, s. 18.

${ }^{10}$ Tabu to obejmowało przede wszystkim kontakt z krwią i śmiercią. Kalał on rytualnie, a zatem były nim objęte osoby parające się pewnymi zawodami, na przykład grabarze, garbarze, rzeźnicy, których określano wcześniej jako eta lub burakumin. Więcej: I. Neary, Burakumin in Contemporary Japan, s. 487-504.

${ }^{11}$ Zainichi (在日, dosł. „przebywanie w Japonii”) jest to określenie osób mieszkających w Japo- 
Owym waldenfelsowskim „my” była grupa etniczna Yamato z rejonów centralnych, położonych nad Morzem Wewnętrznym. To oni tworzyli historię, ubierając ją nieco później w otoczkę mitologiczną, aby przydać sobie większego znaczenia. Ród cesarski, pierwotnie tylko primus inter pares, został wyprowadzony od boskiej protoplastki, bogini Amaterasu, która stanęła na czele panteonu japońskiego, co przełożyło się bardzo szybko na organizację państwa. Ród ten stał się centralnym filarem, wokół którego powstała struktura Yamato, rozciągająca się koncentrycznie dookoła centrum. Na obrzeżach tej struktury znajdowały się plemiona, które opierały się władzy Yamato. Na wschodzie byli to Emishi, czy też Ajnowie ${ }^{12}$, a na zachodzie przede wszystkim wojowniczy Kumaso. Tereny zamieszkiwane przez te grupy były również miejscem przebywania lokalnych bóstw pod rozmaitą postacią. Przeważały wśród nich postaci wężowe, ale bóstwa bardzo często pojawiały się też pod postacią odyńców lub jeleni ${ }^{13}$. W mitologii bóstwa te bądź to uznawały wyższość bóstw Yamato, bądź też musiały zostać zbrojnie pokonane przez bohaterów i tym samym znikały z kart historii. Tego typu mity należy rozumieć jako analogie kontaktów międzyetnicznych - niekiedy cesja władzy przebiegała dobrowolnie, a czasami właśnie na drodze podboju.

W tym miejscu należy też przytoczyć definicję grupy etnicznej, bowiem tym pojęciem będę się posługiwała przy opisie dynamiki zmian politycznych i kulturowych na rubieżach formującego się państwa Yamato. Pojęcia tego używam za Antoniną Kłoskowską, dla której grupa etniczna to:

[...] mała społeczność powiązana ściśle z terytorium, które ma dla niej znaczenie nie tylko praktyczne, jako podstawa bytu, ale także symboliczno-magiczne. Jest to grupa bezpośrednich nawykowych styczności, powiązana związkami sąsiedzkimi, o kulturze folklorystycznej, ludowej, bardzo jednolitej dla całej społeczności i mało zmiennej, tradycyjnej. Jej członkom brak świadomości historycznej i samorefleksji, ale ze względu na bliskość kontaktów i nawykowy charakter podobieństwa zachowań stanowią oni ścisłą wspólnotę ${ }^{14}$.

nii, bardzo często od pokoleń, ale nieposiadających japońskiego obywatelstwa. Więcej na temat problemu zainichi: Japan's Minorities. The Illusion of Homogeneity, M. Weiner (red.); J. Lie, Zainichi (Koreans in Japan).

${ }^{12}$ Niektórzy z badaczy utożsamiają Emishi z Ajnami. Por. P. Varley, Kultura japońska.

${ }^{13}$ Por. M. Y. Aoki, Records of Wind and Earth. A Translation of Fudoki with Introduction and Commentaries.

${ }^{14}$ A. Kłoskowska, Kultury narodowe u korzeni, s. 19. 
Według tej definicji zarówno Yamato, jak i podbijane przez nich społeczności na granicach należały do odmiennych grup etnicznych, różniących się tradycjami, mitami, a także bóstwami. W mitologii oficjalnej, zawartej chociażby w kronice Kojiki, bóstwa grupy Yamato bądź to podbijały, bądź też zjednywały sobie bóstwa terenów, przez które przechodził orszak boskiego potomka. Podbite bóstwa lokalne bardzo często traciły swoje prerogatywy, przenoszone od tego momentu na bóstwa Yamato.

Na temat tsuchigumo ukazały się między innymi artykuły Fukushimy Yoshikazu ${ }^{15}$ i Reider Noriko T. ${ }^{16} \mathrm{~W}$ opracowaniach tych problem badawczy został ujęty z różnych perspektyw. Fukushimę interesowała geneza samego terminu i rozważania dotyczące występowania tsuchigumo w tekstach najstarszych, takich jak kroniki czy też opisy ziem fudoki, Reider z kolei zajęła się tłumaczeniem i interpretacją ilustrowanego zwoju opowiadającego o pokonaniu tsuchigumo przez dzielnego wojownika Minamoto no Yorimitsu ${ }^{17}$. Pozycji poświęconych pająkowi ziemnemu jest jednak zdecydowanie więcej. Celem niniejszego artykułu jest zbadanie konstruktu tsuchigumo jako procesu demonizacji Obcego w rozumieniu waldenfelsowskim, w kontekście kulturowym. Proces ten, obecny w początkach formowania się państwowości japońskiej, został wykorzystany także przez Utagawę Kuniyoshiego jako środek przekazu satyry wymierzonej w społeczeństwo. w dalszym ciągu wpisuje się to jednak w ten sam paradygmat - odczłowieczenia, zdemonizowania przeciwników (etnicznych, politycznych bądź społecznych). Ukazanie gatunkowej Obcości dystansuje te postaci od bohaterskich wojowników, pokonujących zarówno pająka, jak i jego demoniczną czeredę. W ten sposób tworzy się granica ludzkie - nie-ludzkie, a śmierć demonicznego przeciwnika jest albo zasłużona, albo też mniej istotna od śmierci człowieka. Zarówno istnienie, jak i śmierć takich istot sprowadza się zatem do poziomu niższego niż ludzki, a czytelnik czy słuchacz mogą odetchnąć z ulgą, kiedy okrutny, terroryzujący okolicę pająk zostaje zgładzony. W przypadku historycznych tsuchigumo nikt nie toczył walk z gigantycznymi pająkami. Walczono

15 Y. Fukushima, Tsuchigumodenki no seiritsu ni tsuite 土蜘蛛伝記の成立について [O powstaniu legend tsuchigumo].

${ }^{16}$ N. T. Reider, Tsuchigumo sōshi: The Emergence of a Shape-Shifting Killer Female Spider, S. $55^{-83}$.

${ }^{17}$ Nazwiska japońskie będą w niniejszym artykule przedstawiane zgodnie z tradycją azjatycką, czyli najpierw nazwisko, a potem imię. Sam Yorimitsu był postacią historyczną (żył w latach ok. 944/948-1021), wraz z czterema towarzyszami stał się bohaterem licznych historii opowiadających o zmaganiach $\mathrm{z}$ demonami. 
z opornymi plemionami, ludźmi z krwi i kości. Jednak już trzy wieki później dokonano przeniesienia obrazu kulturowego - plemiona zmieniły się $\mathrm{w}$ niebezpieczne pająki, a ich uśmiercanie było tylko i wyłącznie działaniem dla dobra Yamato, usuwaniem demonicznych istot, a nie rzezią miejscowej ludności.

Tsuchigumo pojawiają się $\mathrm{w}$ fudoki $i^{18}$ jako nazwa własna grup wrogich Yamato i prowadzących nieustanną walkę o zachowanie samodzielności na zachodzie. Tylko jeden raz nazwa ta została użyta w Kojiki ${ }^{19}$, z kolei w Hizen fudoki pojawia się jedenaście razy, jednak zapisywana jest zupełnie innymi znakami $k a n j i^{20}$, które nie powtarzają się w innych źródłach. Różny sposób zapisu może świadczyć o próbach usystematyzowania pewnego pojęcia $^{21}$. Pierwotnie słowo tsuchigumo mogło nawet nie mieć nic wspólnego z pająkiem. Dopiero przejęcie pisma z Chin postawiło twórców najstarszych tekstów przed nie lada problemem - w jaki sposób, jakimi znakami zapisać pojęcie, które oznaczało coś bardzo nieuchwytnego, stojącego poza kręgiem familiarnych znaczeń? Kompilatorzy na różne sposoby próbowali sobie z tym poradzić. Ponieważ - gumo w słowie tsuchigumo kojarzyło się z pająkiem, użycie konkretnych znaków narzucało się w sposób oczywisty. Status cywilizacyjny tsuchigumo jest dużo niższy niż przedstawicieli Yamato, choć zapewne kompilatorzy kronik i fudoki przenieśli współczesne im wartości kulturowe w przeszłość. Arystokracja i literati VIII wieku byli już pod ogromnym wpływem cywilizacji Chin, tworząc państwo oparte na wzorach administracji sąsiada. Kilka wieków wcześniej wszystkie grupy były na podobnym poziomie zaawansowania cywilizacyjnego, z nielicznymi wyjątkami - były to te federacje plemienne, którym udało się nawiązać i utrzymać choćby sporadyczne kontakty handlowe z kontynentem. Przykładem była

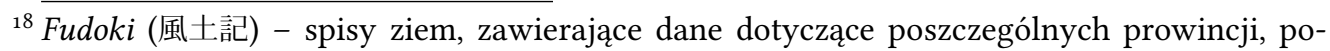
cząwszy od topografii, a skończywszy na pieśniach i legendach z regionu, opracowane na polecenie cesarskie na początku VIII wieku.

${ }^{19}$ Kojiki (古事記) - pierwsza kronika japońska, stanowiąca zapis dziejów Japonii od stworzenia świata po VI wiek.

${ }^{20}$ Kanji (漢字) - ideogramy chińskie. Zanim doszło do włączenia znaków pisma chińskiego w system pisma japońskiego, język chiński spełniał funkcję języka oficjalnego, lingua franca Azji Wschodniej. Najwcześniejsze teksty były spisywane bądź po chińsku, bądź też w hybrydowym systemie, będącym zapisem w znakach oddających najbliższe fonetyczne odczytanie japońskie.

${ }^{21}$ Znaki służące do zapisu man’yōgany były zróżnicowane, stąd kilka sposobów zapisu tego samego dźwięku. 
federacja rządzona przez królową Himiko ${ }^{22}$ w III wieku n.e., o której wiadomo, że otrzymała z Chin brązowe lustra i złotą pieczęć - podówczas wyznacznik statusu i potęgi. Wysłanie okrętu z poselstwem do Chin wiązało się z olbrzymim kosztem, w związku z czym tylko najpotężniejsze federacje mogły sobie na taki gest pozwolić.

Owe grupy, które były obce etnicznie Yamato albo też opierały się podbojowi, zostały wyrzucone z kręgu człowieczeństwa i zredukowane poprzez porównanie do zwierząt, w tym przypadku do pająków. Ich opis przedstawia wychudzone postaci, odziane $\mathrm{w}$ ubrania zrobione $\mathrm{z}$ włókna roślinnego i niewyprawionych skór. Byli brudni, zamieszkiwali wydrążone przez siebie jamy w zboczach wzgórz i poruszali się często na czworaka, co miało przypominać właśnie sposób poruszania się pająków ${ }^{23}$. Według Sahary Makoto nazwa tsuchigumo może pochodzić od zmodyfikowanego słowa tsuchigomori, które oznacza „ukrywać się w głębi ziemi” ${ }^{24}$. Większość niepokornych grup prowadziła z Yamato walki metodą partyzancką, często atakując z ukrycia, na przykład w parowach. $Z$ tej przyczyny nazwa może być również aluzją do sposobu, w jaki się zachowywali - po prostu uciekając i kryjąc się przed wzrokiem wojowników. Warto w tym miejscu nadmienić, że wśród przywódców grup tsuchigumo były również kobiety. Fakt ten predysponował autorów spisujących legendy w VIII wieku, będących już pod wpływem tradycji chińskiej, do anachronicznego uznania struktur owych klanów za niecywilizowane, a co za tym idzie - pozbawione elementów ludzkich.

W Kojiki nazwa zapisana jest za pomocą znaków, które oznaczają posiadanie ogona. Być może jest to aluzja do zwierzęcego futra, jakim byli okryci (co również plasuje ich niżej w hierarchii cywilizacyjnej grup Yamato), albo też do większego owłosienia na ciele (jak było w przypadku Ajnów). $\mathrm{Z}$ drugiej strony dodanie zwierzęcego elementu anatomicznego może stanowić kolejną próbę wyrzucenia opisywanych postaci poza grupę ludzi zezwierzęcenia ich, pozbawienia cech homo sapiens, a tym samym odmowy prawa do istnienia na tych samych warunkach. W dalszym ciągu określenie tsuchigumo odnosiło się do ludzi, ale stali oni poniżej poziomu cywilizacyjnego Yamato, w związku z czym federacja czuła się uprawniona do usunięcia owych przeciwników, podobnie jak usuwało się szkodniki.

${ }^{22}$ Por. J. E. Kidder, op. cit.

${ }^{23}$ Por. M. Y. Aoki., op. cit.

${ }^{24}$ Za: M. Sahara, Taikei Nihon no rekishi 1: Nihonjin no tanjō 体系 日本の歴史 1 日本人の誕生 [Historia Japonii 1: Japończycy i ich początki]. 
Wyobrażenie pająka ziemnego, które przetrwało do dzisiaj, to jednak wpływ epok późniejszych, kiedy istota zwana tsuchigumo stała się bohaterem sztuki teatralnej pod takim samym tytułem ${ }^{25}$. Ustaliła ona kanon wyglądu i zachowania pająka, choć należy również pamiętać o specyfice istot demonicznych w teatrze $n \bar{o}^{26}$. Sztuka ta stała się źródłem późniejszych wyobrażeń oraz przeobrażeń koncepcji pająka ziemnego w kulturze japońskiej, a ponadto utrwaliła negatywne cechy, które od tej pory były asocjowane $\mathrm{z}$ tą istotą, na przykład przebiegłość, krwiożerczość i okrucieństwo, zmiennokształtność. Tsuchigumo opowiada dość prostą historię: Minamoto no Yorimitsu (w legendach znany także jako Raikō) leży złożony chorobą, na którą nie pomagają żadne lekarstwa. Pewnej nocy odwiedza go mnich, dopytując o zdrowie, a gdy ten prosi go o wyjawienie imienia, w odpowiedzi słyszy wiersz z antologii poezji Kokinsh $\bar{u}^{27}$, w którym wspomina się pająka. Raikō nie potrzebował niczego więcej, by odgadnąć tożsamość mnicha, który faktycznie okazał się pająkiem, ale nie był w stanie go zabić. Służący Raikō, wypełniając polecenie pana, wziął jego miecz i idąc śladem krwi pozostawionej przez uciekającego mnicha, odszukał pająka, po czym go uśmiercił ${ }^{28}$. Choroba, która trapiła wojownika, od razu ustąpiła, zorientowano się zatem, że jej przyczyna nie była naturalna. Pająk zapewne chciał go osłabić fizycznie i pożreć, kiedy Raikō nie był w stanie stawić oporu i gdy nie było przy nim jego wiernych towarzyszy.

Wyraźne jest tym samym nawiązanie do starszych historii, w których tsuchigumo uciekali przed wojownikami państwa Yamato i kryli się pośród wzgórz i jaskiń. Pająk pod postacią mnicha, gdy został rozpoznany i raniony,

${ }^{25}$ Więcej na temat sztuki zob. K. Kanze, Utaikata kōza: Tsuchigumo 謡い方講座一土蜘蛛 [Śpiew teatru nō - tsuchigumo]; K. Komatsu, Nō no naka no ikai (5) Katsuragisan: Tsuchigumo 能のなかの異界(5) 葛城山：土蜘蛛 [Świat nadnaturalny w teatrze nō (5) Góra Katsuragi: tsuchigumo].

${ }^{26}$ Teatr $n \bar{o}$ (能) - najstarszy z tradycyjnych teatrów japońskich, teatr maskowy, hieratyczny i dostojny. Sztuki opowiadają między innymi historie o bogach, wojownikach, namiętnościach, demonach, kobietach. Istota demoniczna teatru nō to najczęściej personifikacja namiętności ludzkich przeszkadzających w odrodzeniu się duszy, a nie prawdziwy demon. Więcej na temat teatru japońskiego zob. E. Żeromska, Japoński teatr klasyczny. Korzenie i metamorfozy, t. 1: nō, kyōgen.

${ }^{27}$ Skrócona wersja Kokinwakashū. Jest to antologia poezji japońskiej (waka) ukończona około 920 roku na polecenie dwóch cesarzy - Uda oraz Daigo. Kompilatorami byli: Ki no Tsurayuki, Ki no Tomonori, Ōshikōchi no Mitsune oraz Mibu no Tadamine. Zob. Dziesięć tysięcy liści. Antologia literatury japońskiej, W. Kotański (tłum.).

${ }^{28} \mathrm{Za}$ : Noh database, [www 01]. 
uciekł na wzgórza, gdzie miał swoją kryjówkę, ale został wytropiony i po niełatwej walce pokonany. W sztuce tej zniknęły grupy etniczne, ich przywódcy i zbuntowane klany, pojawiła się natomiast samodzielna, myśląca istota pod postacią pająka, której jedynym związkiem z naturą ludzką była umiejętność przybrania postaci człowieka. Doszło zatem do rozpadu dwoistego konceptu tsuchigumo na bardziej prominentną istotę demoniczną oraz coraz bardziej zapominane obce grupy etniczne u zarania państwowości. Teatr $n \bar{o}$ został ukształtowany na przełomie XIV-XV wieku, a zatem w czasach, gdy Japonia cieszyła się względnym spokojem, dominowało przekonanie o homogeniczności narodu, a burzliwe początki Yamato zostały zepchnięte w niepamięć. Nazwa tsuchigumo przetrwała, ale zaczęła oznaczać co innego - istotę pajęczą per se, a nie pejoratywne określenie krnąbrnych grup i przywódców, których w celu poniżenia zaliczono do zwierząt. Wizualnie najczęściej była ona przedstawiana jako olbrzymi pająk o ubarwieniu czarno-żółtym lub czarno-pomarańczowym. Zapewne wpływ na taki dobór kolorów miał występujący w Chinach gatunek pająka tygrysiego ${ }^{29}$. Ten zabieg świadczy też o późniejszym źródle wyobrażenia tsuchigumo jako demonicznej istoty zwierzęcej. Wiadomości o takim pająku mogły przybyć do Japonii wraz z nowymi prądami i ideami z kontynentu. Pająk ten spędza dzień zasypany w wykopanej przez siebie norce i być może wiadomości o takim zachowaniu przeszły do Japonii, gdzie zostało ono skojarzone z obcymi klanami, które również mieszkały w jaskiniach i wydrążonych w zboczach grotach. Doszło zatem do nałożenia obrazu pająka na grupy etniczne i to skojarzenie stało się tak silne, że do dziś kwestia, czy pierwszy był pająk, czy nazwa plemion, pozostaje nierozwiązana.

Tryptyk autorstwa Utagawy Kuniyoshiego pt. Minamoto Raikō i pająk ziemny (Minamoto Raikō kōkan tsuchigumo saku yōkai no zu) przedstawia uśpionego Raikō i jego towarzyszy, za którymi przesuwa się orszak tsuchigumo, składający się z rozmaitych istot demonicznych okresu Edo. Melinda Takeuchi, która przeprowadziła drobiazgową analizę dzieła ${ }^{30}$, stwierdza, że tryptyk przedstawia w sposób zawoalowany, przy użyciu istot demonicznych, realne problemy i bolączki ówczesnego społeczeństwa japońskiego.

${ }^{29}$ Jest to gatunek Haplopelma, należący do tarantul. W środowisku naturalnym zagrzebują się w norkach wyłożonych jedwabną wydzieliną, gdzie czekają na noc, kiedy przypada czas ich aktywności. Za: M. S. Zhu, R. Zhang, Revision of the Theraphosid Spiders from China (Araneae: Mygalomorphae), s. 425-447.

${ }^{30}$ M. Takeuchi, Kuniyoshi's „Minamoto Raikō" and „the Earth Spider”: Demons and Protest in Late Tokugawa Japan, s. 5. 
Najczęściej postać śpiącego Raikō była identyfikowana z nieudolnym shōgunem Ieyoshim, postaci wróbli - z tancerzami, których działalność mocno kontrolowano i którzy byli uważani za element szkodliwy, postaci $k a p p^{31}-$ z prostytuującymi się aktorami itp..$^{32}$ Dzieło to stanowi jednocześnie ostatnie twórcze użycie motywu tsuchigumo w kulturze Japonii. Nigdy już pająk ziemny nie stał się głównym bohaterem przedstawienia wizualnego. $\mathrm{W}$ dalszym ciągu charakterystyczne cechy pająka, czyli jego Obcość i Inność, zostały zachowane, nawet jeśli on sam i demony są tylko alegorią innych zawodów i prawdziwych postaci. Jest to jednak cały czas element buntowniczy, zagrażający konfucjańskiemu ładowi społecznemu, stanowiący potencjalną groźbę. Co więcej, Kuniyoshi zmarł w 1861 roku, a zatem jego twórczość przypadła na ostatnie dekady shōgunatu rodu Tokugawa, okresu nietrafionych reform, niepokojów społecznych, buntów, samowoli oddalonych od Edo regionów, a przede wszystkim zwiększonej obecności obcokrajowców w samej Japonii i w jej bliskim otoczeniu. Wszystkie elementy stwarzające zagrożenie dla ładu państwa zostały zatem zobrazowane jako tsuchigumo w asyście demonicznej sfory. Była to ostatnia taka próba zdemonizowania wszystkich, których uznawano za wrogów państwa.

Ciekawostką topograficzną dotyczącą pająków ziemnych jest istnienie niewielkich wzniesień w niemal całym kraju, zwłaszcza w rejonie centralnym, uważanym za kolebkę japońskiej cywilizacji, które według legend skrywają ciała pająków bądź też odcięte głowy tych istot. W centralnej i zachodniej Japonii można znaleźć kilka miejsc, które noszą nazwę Pajęcze Wzgórze - Kumozuka. Większość z nich nawiązuje do legend epok wcześniejszych. Na wyspie Kyūshū w mieście Miyama (prefektura Fukuoka) znajduje się niewielki pagórek zwany Kumozuka kofun ${ }^{33}$, który według legendy pochodzi z czasów cesarza Keikō (panującego w latach 71-130) ${ }^{34}$. Cesarz udał się na wyspę w celu podbicia tych terenów i pokonania krnąbrnych klanów.

${ }^{31} \mathrm{Kappa}$ - demon wodny, zamieszkujący głównie błotniste brzegi rzek. Kappy były istotami bardzo groźnymi - wciągały do rzek konie, topiły ludzi, dokonywały gwałtów na kobietach. Przedstawiano je jako niewysokie postaci, o zielonkawej bądź szarej skórze, z żółwim pancerzem na plecach, rzadkimi włosami otaczającymi wgłębienie na czubku głowy i z ptasim dziobem. Kappy skojarzono z aktorami z uwagi na określenie tej grupy jako kawaramono - „osoby z wyschniętego dna rzeki”, zatem zachowano element rzeczny łączący alegorię i rzeczywistą grupę.

${ }^{32}$ M. Takeuchi, op. cit., s. 14 .

33 Słowo kofun oznacza kurhan.

34 Są to daty legendarne. O pierwszych historycznych władcach można mówić dopiero od przełomu VI i VII wieku. 
Na swojej drodze napotkał jednak tsuchigumo, którym przewodziła Taburatsuhime. Została ona pokonana w bitwie, a nad jej ciałem usypano niewielki kurhan $^{35}$. Drugie ze znanych miejsc znajduje się w okolicy, w której swoje legowisko miał pająk pokonany przez Raikō (czy też jego służącego bądź, według innych legend, przez jego wiernych towarzyszy) - w Kioto, pomiędzy świątynią Higashi Mukai Kannon-ji a świątynią Jōhonrendai-ji ${ }^{36}$. Oprócz tego jest jeszcze jedno miejsce w Gose, w prefekturze Nara, przy świątyni shintōistycznej poświęconej Katsuragihitokotonushi - zwie się ono Kumogutsu, czyli Jaskinia Pająka. Tsuchigumo, który przebywał w tych okolicach i terroryzował miejscową ludność, został zgładzony przez samego Minamoto Raikō ${ }^{37}$.

Losy tsuchigumo to historia pewnego wyobrażenia, które pierwotnie było używane na oznaczenie niepokornych, zbuntowanych, odmiennych etnicznie grup na peryferiach formującego się państwa Yamato. Następnie w korpus znaczeń słowa tsuchigumo włączono istoty pajęcze, rozrośnięte do monstrualnych rozmiarów i krwiożercze. W następnej epoce do tego imaginarium dołączyły samodzielnie istniejące istoty demoniczne pod postacią zmiennokształtnego pająka, by wreszcie stać się zapomnianym elementem wyobrażeń demonicznych okresu Edo. Forma tsuchigumo jest wyobrażeniem Obcości, zagrożenia dla wspólnotowości, elementem heterogenicznym i subwersyjnym, niebezpieczeństwem, które czeka na właściwy moment, by rozbić harmonię społeczną. Być może z tego względu w okresie Edo użyto postaci pająka i jego czeredy w celu przedstawienia tych członków społeczeństwa, których uważano za stwarzających zagrożenie, zwłaszcza moralne. Mimo że obraz ten stracił pierwotne znaczenie, w dalszym ciągu oznaczał owo waldenfelsowskie wykluczenie z kręgu „my”. Wciąż pozostaje on symbolem Obcości, inności i zagrożenia.

35 Zob. Kofun meguri walking, [www 02].

${ }^{36}$ Zob. Kumozuka, [www 03].

37 Zob. biuletyn informacyjny miasta Gose: Takama no kumogutsu to uguisu densetsu 高天の蜘蛛窟と鶯伝説 [Legendy z Takama o faskini Tsuchigumo i stowiku]. 


\section{Bibliografia}

1. Antoni K., Izumo as the 'Other' : Construction vs. Reality, „Japanese Religions” 30 (1-2/2005), s. 1-20.

2. Aoki M. Y., Records of Wind and Earth. A Translation of Fudoki with Introduction and Commentaries, Association for Asian Studies, Ann Arbor 1997.

3. BABA K., Tsuchigumo no kenkyū: fō 「土蜘蛛」の研究-上- [Badania nad tsuchigumo, t. 1], [w:] Kikan hōgaku 59/1989.

4. BABA K., Tsuchigumo no kenkyū: Chū「土蜘蛛」の研究-中- [Badania nad tsuchigumo, t. 2], [w:] Kikan hōgaku 6o/1989.

5. BABA K., Tsuchigumo no kenkyū: Ge「土蜘蛛」の研究-下- [Badania nad tsuchigumo, t. 3], [w:] Kikan hōgaku 62/1990.

6. Bush C., The Other of the Other? Cultural Studies, Theory, and the Location of the Modernist Signifier, "Comparative Literature Studies” 42 (2/2005), s. 162-180.

7. Caspari E., Robbins K., Animal Life In Nature, Myth and Dreams, Asheville 2003 .

8. Dziesięć tysięcy liści. Antologia literatury japońskiej, W. Kotański (tłum.), Warszawa 2012.

9. Funushima Y., Tsuchigumodenki no seiritsu nitsuite 土蜘蛛伝記の成立に ついて [O powstaniu legend tsuchigumo], Kansai Gakuin University Repository, 1971.

10. Grayson J. H., Susa-no-o. A Culture Hero from Korea, „Japan Forum” 14 (3/2007), s. 465-487.

11. Japan's Minorities. The Illusion of Homogeneity, M. Weiner (red.), New York - London 1997.

12. KANZE K., Utaikata kōza: Tsuchigumo 謡い方講座一土蜘蛛 [Śpiew teatru $n \bar{o}-t$ suchigumo], Kanze, Tokio, 19 (7/1952).

13. Kidder J. E., Himiko and Japan's Elusive Chiefdom of Yamatai: Archaeology, History, and Mythology, Honolulu 2007.

14. KŁoskowska A., Kultury narodowe u korzeni, Warszawa 1996.

15. Kojiki 古事記 [Kronika dawnych wydarzeń], [w:] Kojiki. Norito 古事記 - 祝詞 [ttumacznie], NKBT: Nihon koten bungaku taikei 日本古典文学 大系 [Kolekcja japońskiej literatury klasycznej], Iwanami shoten, Tokio $1 / 1958$. 
16. Komatsu K., Nō no naka no ikai (5) Katsuragisan: Tsuchigumo 能のなか の異界 (5) 葛城山：土蜘蛛 [Świat nadnaturalny w teatrze nō (5) Góra Katsuragi: tsuchigumo], Kanze, Tokio 70 (12/2003).

17. Кивота Y., Tsuchigumo kenkyū ni okeru kadai to tenbō 土蜘蛛研究に おける課題と展望 [Tematy i zagadnienia w badaniach nad tsuchigumo], „Komazawa shigaku” 駒沢史学 86/2016, s. 167-175.

18. LIE J., Zainichi (Koreans in Japan), Berkeley - Los Angeles 2008.

19. Matsumae T., Origin and Growth of the Worship of Amaterasu, Tenri University, 1977.

20. Matsumoto Y., Tsuchigumoron 土蜘蛛論 [Teorie tsuchigumo], „Shigaku” 史学 25 (4/1952), s. 434-455.

21. Neary I., Burakumin in Contemporary Japan, [w:] Japan's Minorities. The Illusion of Homogeneity, M. Weiner (red.), New York-London 1997, s. $487-504$.

22. OkiURA K., Nihon rettō no senjūmin: Tsuchigumo - sono denshō no chi o aruku 日本列島の先住民 - 土蜘蛛-その伝承の地を歩く [Pierwotni mieszkańcy Archipelagu Japońskiego: tsuchigumo - wędrówki po ich legendarnych ziemiach], „Kanagawa Daigaku hyōron” 神奈川大学評論, 42/2002, s. $30-52$.

23. ReIder N. T., Tsuchigumo sōshi: The Emergence of a Shape-Shifting Killer Female Spider, „Asian Ethnology” 72 (1/2013), s. 55-83.

24. Sahara M., Taikei Nihon no rekishi 1: Nihonjin no tanjō 体系 日本の歴史 1 日本人の誕生 [Historia Japonii. 1: Japończycy i ich początki], Tōkyō 1992.

25. Shiratori K., Tsuchigumo densetsu ni tsuite 土蜘蛛傳説に就いて [O legendach na temat tsuchigumo], „Minzokugaku kenkyū” 民族學研究, 4 (3/1938), s. 373-383.

26. Takama no kumogutsu to uguisu densetsu 高天の蜘蛛窟と鶯伝説 [Legendy z Takama o Jaskini Tsuchigumo i stowiku], Gose 905/ 2016.

27. Takeuchi M., Kuniyoshi's „Minamoto Raikō” and „the Earth Spider”: Demons and Protest in Late Tokugawa Japan, „Ars Orientalis”, 17/1987, s. 5-38.

28. VARley P., Kultura japońska, M. Komorowska (tłum.), Kraków 2006.

29. Waldenfels B., Topografia obcego. Studia z fenomenologii obcego, J. Sidorek (tłum.), Warszawa 2002.

30. Ż̇romsка E., fapoński teatr klasyczny. Korzenie i metamorfozy, t. 1: nō, kyōgen, Warszawa 2010. 
31. Zhu M. S., Zhang R., Revision of the Theraphosid Spiders from China (Araneae: Mygalomorphae), ,Journal of Arachnology”, 36/2008, s. 425447.

\section{Źródła internetowe}

[www 01] http://www.the-noh.com (dostęp: 20.11.2016)

[www 02] http://kofunmeguriwalking.web.fc2.com/kumozuka.html (dostęp:

22.11.2016)

[www 03] http://hota12.web.fc2.com/index/kumozuka.html (dostęp: 22.11.2016) 


\title{
Abstract, keywords, about the author
}

\begin{abstract}
The Idea of Tsuchigumo as the Mythologisation of the Threat Tsuchigumo -that is, "ground spider" or "earth spider" - is a malevolent entity existing deep inside Japanese legends. Narratives about these bloodthirsty and violent spiders harassing Yamato soldiers appear as early as the 8th century, although their origins lie deeper. Tsuchigumo is not only a giant spider, vanquished by Emperors or warriors, but the name also signifies many ethnically heterogenous groups fighting the dominating Yamato group before the 8th century. Calling the unruly and defiant clans and ethnic groups tsuchigumo put the Yamato clans within the human sphere and their opponents outside of it. This process led to the demonisation of everything that lay beyond the familiar circle, labelling it as Other, Strange, and finally - Non-human, a Demon. Hence tsuchigumo became a demonic creature, existing on the fringe of civilisation, an unwanted and disruptive element that needed to be thrown into oblivion for the rest of the world to properly function. The article seeks to establish a connection between the roots of the concept of tsuchigumo and the process of demonising the Other as seen in Japanese culture.
\end{abstract}

Keywords: Japan, spider, Otherness, tsuchigumo

Renata IwICKA holds an MA in Japanese and Chinese Studies and a $\mathrm{PhD}$ in Cultural Studies. Her primary areas of academic interest include demonology, the history and culture of East Asia (primarily pertaining to the Korean Peninsula and Japan), modern popular culture, and mythology.

Selected publications: Chaos wspótczesności - Japonia okresu Taishō jako źródto inspiracji Akutagawy Ryūnosuke (The Chaos of Modernity - Taishō fapan as the Source of Inspiration for Akutagawa Ryūnosuke) [in:] Między Wschodem a Zachodem. W poszukiwaniu źródet i inspiracji, red. A. Bednarczyk, M. Kubarek, M. Szatkowski, Torun, 2016, p. 93-104; Użycie roślin w telewizyjnych serialach fantastycznych (Plants in Fantasy Television Series), „Maska” 27/2015, p. 159-170; Czy kultura koreańska zatopiła Sewol? (Has the Korean Culture Drowned Sewol?) [in:] Kultury Wschodu wświecie procesów globalizacyjnych, red. P. Mróz, M. Ruchel, A. I. Wójcik, Kraków, 2015, p. 113-140.

E-MAIL: grad_ecmaise@yahoo.com 